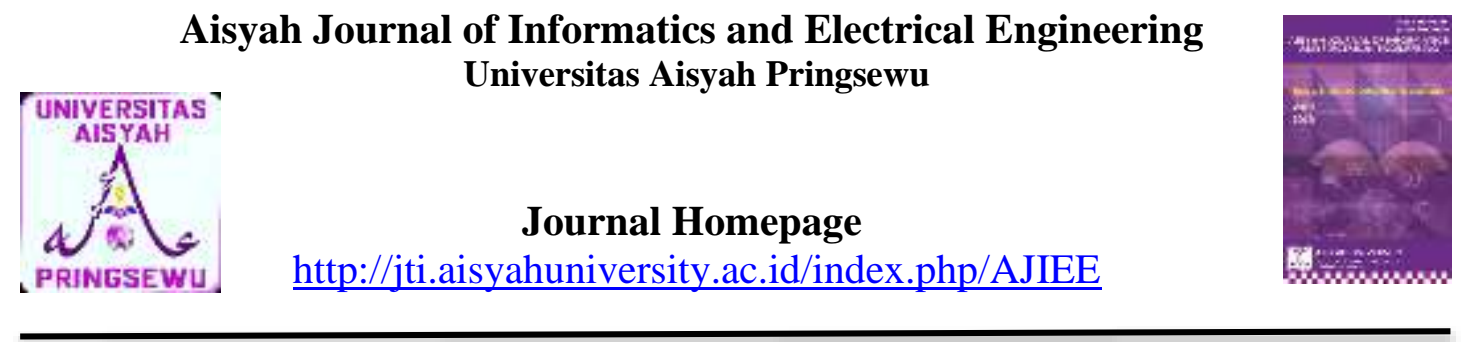

\title{
FACE RECOGNITION UNTUK SISTEM KEAMANAN RUANGAN ARSIP UNIVERSITAS AISYAH PRINGSEWU MENGGUNAKAN MATLAB
}

\author{
Agustinus Eko Setiawan' ${ }^{1}$, Ahmad Ahlun Nazar ${ }^{2}$ \\ ${ }^{1,2}$ Program Studi Teknik Informatika, Fakultas Teknologi dan Informatika \\ Universitas Aisyah Pringsewu \\ Email: tynusKicenk@gmail.com
}

\begin{abstract}
Abstrak
Ruang arsip adalah tempat penyimpanan dokumen-dokumen penting, maka dalam hal ini tidak semua orang bisa mengakses ruangan tersebut. Sebagai keamanan ruangan arsip, dalam penelitian ini peneliti akan membuat sistem keamananan ruangan. Sistem keamanan yang akan dibangun yaitu face recognition, face recognition merupakan salah satu bidang yang terdapat pada digital image processing dimana peruntukan dari face recognition itu sendiri bermacam-macam dimulai dari sistem kehadiran maupun sistem keamanan, dalam penelitian ini akan dirancang sebuah sistem pengenalan wajah sebagai akses untuk keluar masuk ruangan arsip di Universitas Aisyah Pringsewu, dimana sistem tersebut dirancang dengan menggunakan bahasa pemrograman Matlab R2013a. Yang nantinya diharapkan dapat terintegrasi dengan suatu sistem kendali yang berfungsi sebagai alat pengunci pintu. Dalam penelitian ini proses identifikasi wajah dilakukan hanya sebatas simulasi dengan hasil penelitian mencapai sekitar $90 \%$ dari 10 percobaan.
\end{abstract}

Kata kunci: Face Recognition, Simulasi, Sistem Keamanan, Matlab R2013a 


\section{Pendahuluan}

Universitas Aisyah Pringsewu adalah Universitas Swasta yang sedang berkembang di wilayah Lampung yang terletak di Kabupaten Pringsewu. Dalam hal ini, banyak sekali dokumen-dokumen penting yang harus dijaga agar tidak tercecer atau hilang. Untuk menjaga suatu keamanan di ruangan arsip Universitas Aisyah Pringsewu, sangat perlu dibagun suatu sistem keamanan ruangan. Sistem yang di bangun dengan cara Image Processing, Image processing adalah suatu sistem di mana proses dilakukan dengan masukan berupa image dan hasilnya juga berupa image (1). Digital image processing merniliki banyak aplikasi seperti pada bidang penginderaan jarak jauh, robotik, pemetaan, biomedis, dan sebagainya. Perlengkapan Digital image processing minimal terdiri atas alat pemasukan data image berupa digitizer atau scanner, komputer, dan alat penyimpanan data dengan kapasitas yang besar. Melalui sebuah webcam penelitian ini dimaksudkan untuk merealisasikan pengetahuan dibidang image processing khususnya dalam hal pengenalan wajah atau yang lebih dikenal dengan teknik face recognition dengan menggunakan metode eigen face.

Pengenalan wajah merupakan salah satu penelitian yang banyak dilakukan dalam beberapa tahun terakhir. Banyak teknik yang digunakan untuk mendeteksi dan mengenali wajah. Langkah pertama pengenalan wajah adalah deteksi wajah (2) (3). Algoritma deteksi wajah seringkali dilaksanakan sebagai tugas pola-klasifikasi biner. Artinya, isi dari bagian tertentu dari suatu gambar diubah menjadi fitur, setelah mana classifier dilatih pada wajah misalnya memutuskan apakah daerah tertentu dari gambar wajah, atau tidak. Seringkali wajah bisa dideteksi oleh algoritma warna, gerak dan basis model. Algoritma wana kulit (4) juga merupakan algoritma yang dipertimbangkan dalam proyek ini karena telah terbukti menjadi isyarat yang berguna dan kuat untuk deteksi wajah. Metode pemodelan warna kulit yang ada termasuk daerah kulit eksplisit didefinisikan, nonparametrik pemodelan kulit distribusi dan pemodelan kulit distribusi parametrik. Metode pertama membangun classifier kulit adalah mendefinisikan secara eksplisit (melalui sejumlah aturan) cluster batas kulit di beberapa titik warna.

Tujuan utama dari penelitian ini sendiri adalah merancang sebuah sistem keamanan ruangan arsip dengan menggunakan deteksi wajah sebagai akses untuk membuka sistem kemanan ruangan itu sendiri, akan tetapi dalam penelitian ini tidak secara langsung dilakukan perancangan perangkat keras melainkan lebih bersifat simulasi dengan menggunakan aplikasi yang telah dirancang sebelumnya.

\section{Landasan teori}

\section{Matlab}

Matlab adalah sebuah bahasa dengan kemampuan tinggi untuk komputasi teknis. MATLAB menggabungkan komputasi, visualisasi, dan pemrogramandalam satu kesatuan yang mudah digunakan di mana masalah dan penyelesaiannya diekspresikan dalam notasi matematik yang sudah dikenal.Nama MATLAB merupakan singakatan dari matrix labolatory. MATLAB awalnya dibuat untuk memudahkan dalam mengakses software matriks yang telah dikembangkan oleh LINPACK dan EISPACK. Dalam perkembangannya, MATLAB mampu mengintegrasikan beberapa software matriks sebelumnya dalam satu software untuk komputasi matriks. Tidak hanya itu, MATLAB juga mampu melakukan komputasi simbolik yang biasa dilakukan oleh MAPLE. 


\section{Eigenface}

Eigen face adalah salah satu algoritma pengenalan wajah yang berdasarkan pada Principle Component Analysis (PCA) yang dikembangkan di MIT. Algoritma Eigen Face secara keseluruhan cukup sederhana. Training Image direpresentasikan dalam sebuah vektor flat (gabungan vektor) dan digabung bersamasama menjadi sebuah matriks tunggal. Eigen Vector kemudian diekstraksi dan disimpan dalam file temporary atau database. Training image kemudian kemudian diproyeksikan dalam feature space, dinamai face space yang ditentukan oleh eigen vektor. Adapun algoritma selengkapnya adalah:

a. Buat Make Eigen Vectors (ImageList, N, M): Image List adalah kumpulan dari $\mathrm{N}$ training image, dimana setiap image adalah W $x$ H pixel. $\mathrm{M}$ adalah jumlah eigen vektor yang harus dibuat.

b. Gabungkan setiap image dalam WH elemen vektor dengan menggabungkan semua baris. Buat Image Matrix sebagai matrik $\mathrm{N}$ x WH berisi semua gambar yang digabung

c. Jumlahkan semua baris pada Image Matrix dan bagi dengan $\mathrm{N}$ untuk mendapatkan rataan gambar gabungan. Kita namakan vektor elemen WH ini dengan $\psi$.

d. Kurangi Image Matrix dengan average image $\psi$. Kita namakan matriks baru ukuran $\mathrm{N} \times \mathrm{WH}$ sebagai $\Phi$.

e. Hitung dot product dari semua kemungkinan pasangan gambar.
Kita mendapatkan L sebagai matrix ukuran $\mathrm{N}$ x $\mathrm{N}$ dimana $\mathrm{L}[\mathrm{i}][\mathrm{i}]=\mathrm{dot}$ product dari $\Phi[\mathrm{i}]$ dan $\Phi[\mathrm{j}]$.

f. Hitung $\mathrm{N}$ eigen value dan eigen vektor yang bersesuiain dari $\mathrm{L}$. ambil eigen vektor $M$ yang memiliki eigen value tertinggi. Setiap Eigen Vektor akan memilki panjang $\mathrm{N}$ elemen.

g. Lakukan perkalian matrik dari setiap $M$ eigen vektor yang terpilih dengan $\Phi$ dan simpan hasilnya yaitu matrik yang berukuran $1 \mathrm{x}$ WH. Simpan juga hasil rataan $\psi$.

\section{Perancangan Sistem}

Prosedur umum dari penggunan metode eigenface mencakup:
a. Initialization
b. Operating
c. Recognition

Dalam penelitian ini diagram blok dari pemanfaatan face recognition seperti terlihat pada gambar berikut:

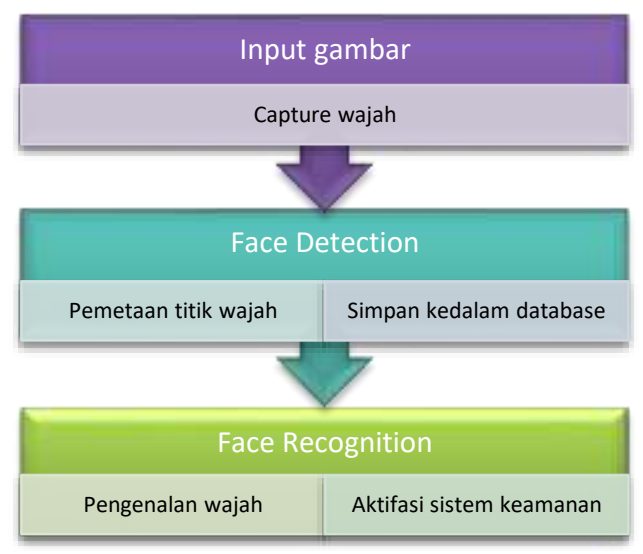

Gambar. 1 Diagram Blok Face Recognition 
penelitian ini dapat dipersentasikan sebesar $90 \%$

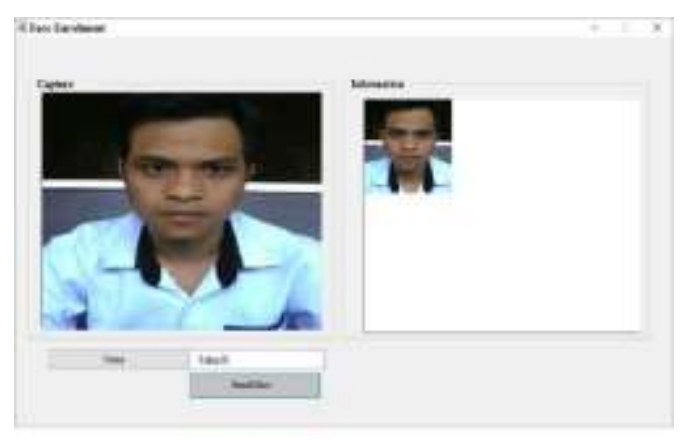

Gambar. 2 Face Capture

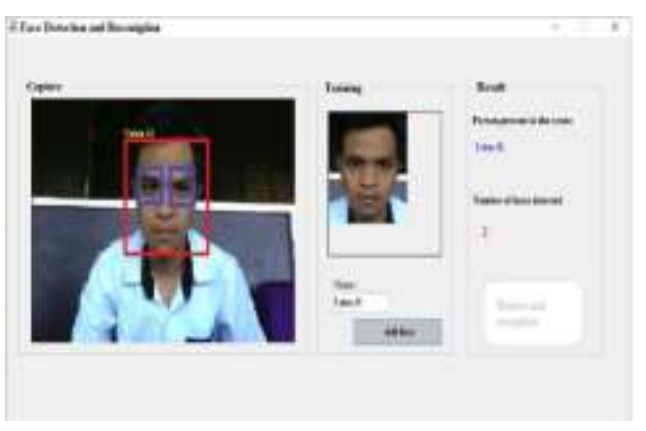

Gambar. 3 Face Detection



Gambar. 4 Face Recognition

\section{Kesimpulan}

Dari hasil penelitian dan simulasi dapat disimpulkan bahwa sistem kemanan rumah dapat diatur dengan menggunakan face recognition, dari hasil percobaan yang dilakukan sebanyak 10 kali terdapat 1 kali kegagalan dengan demikian tingkat akurasi dari face recognition dalam

\section{Daftar pustaka}

1. Basuki, A, Jozua, F P and Faturochman. Pengolahan citra digital denganmenggunakan Visual Basic. Yogakarta : Graha Ilmu, 2005.

2. Singgalen, Rinaldo. Facial Recognition System as a Storage Locker Access. Telekontran, Vol. 5,No. 2, Oktober 2017.

2. Humain and machine recognition of faces: A survey. Chellappa, R, Wilson, C L and Sirohey, C. s.l. : IEEE, 1995.

3. Face recognition: A Literature review. Tolba, A S, El-Baz, A H and El-Harby, A A. s.l. : International Journal of Signal Processing, 2006, Vol. 2.

4. A Survey on pixel-based skin color detection technique. Vezhnevets, $\mathrm{V}$, Sazonov, V and Andreeva, A. s.l.: Graphicon, 2003. 